\title{
Energy Efficiency in a New University Campus: Preliminary Findings
}

\author{
Elmuradov D. B. ${ }^{1}$, Mat Zali S. ${ }^{2}$, Hanafi N. H. ${ }^{2}$, Mohd. Zain Z. ${ }^{3}$, Za'aba S. K. ${ }^{4}$ \& Jusoh M. S. ${ }^{1}$ \\ ${ }^{1}$ School of Business Innovation \& Technopreneurship, University Malaysia Perlis (UniMAP), Kangar, Malaysia \\ ${ }^{2}$ School of Electrical Systems Engineering, University Malaysia Perlis (UniMAP), Pauh Putra Campus, Arau, \\ Malaysia \\ ${ }^{3}$ School of Manufacturing Engineering, University Malaysia Perlis (UniMAP), Pauh Putra Campus, Arau, \\ Malaysia \\ ${ }^{4}$ School of Mechatronic Engineering, University Malaysia Perlis (UniMAP), Pauh Putra Campus, Arau, \\ Malaysia \\ Correspondence: Elmuradov D. B., School of Business Innovation \& Technopreneurship, University Malaysia \\ Perlis (UniMAP), 01000, Kangar, Malaysia. Tel: 60-16-354-0707. E-mail: dr.tamerlane@gmail.com
}

Received: November 10, 2014 Accepted: December 6, 2014 Online Published: January 29, 2015

doi:10.5539/jsd.v8n1p184 URL: http://dx.doi.org/10.5539/jsd.v8n1p184

\begin{abstract}
One of Malaysia's national energy policy's objectives is to promote efficient utilization of energy and the elimination of wasteful and non-productive patterns of energy consumption. The government wishes to intensify energy efficiency (EE) initiatives in a broad range of areas, including in government buildings. University Malaysia Perlis (UniMAP), a Malaysian public institution of higher learning, has been chosen for an action research in the implementation of an energy efficiency program, in line with the government's aspiration. This highly populated organization was an ideal selection for an energy consumption and silent waste research. Research objective was to identify areas of possible energy waste within the Campus. To achieve the objective, 2 projects were selected: one was to reduce energy use of chillers and the other was to find if there is any wastage with wrong setting of luminous flux in specific areas. For the first project, the staging method was adopted, where chillers will be loaded with 15 minutes intervals and for the second, luminous flux was set according to government body's requirement to attain energy saving as initial stage findings showed that luminous flux setting was more than what is required. The results from just these 2 projects demonstrated, that UniMAP was able to save approximately $53,000 \mathrm{kWh}$ of electricity within the research duration. From the preliminary results, it is apparent that more energy wastage analysis within the campus should be carried out in order to maximize potential savings that can be achieved in the future.
\end{abstract}

Keywords: energy, waste, sustainability, chillers, building, educational organizations, cost, and capacity

\section{Introduction}

The Malaysian government's commitment is to promote energy efficiency, as seen in the many government policies and regulations in place. In the line with the government's aspiration, UniMAP started its "Sustainable Campus" program. The first challenge was to find and sustain an active, diverse, and motivated team dedicated to working towards environmental justice and sustainability; volunteers who would selflessly contribute time and engage in the project. The challenge was overcome after the Green Campus workshop, held in June 2012. Staff and student came forward to be chosen as leaders on accepted directions for the study. Result of workshop was impressive and few directions on sustainability study were accepted. Currently the program comprises of 12 Groups and namely:

1) People.

2) Land and Water.

3) Procurement.

4) Waste.

5) Energy Management.

6) Automotive. 
7) Transportation.

8) Climate.

9) Food.

10) Cannibalization.

11) Building Operation and Maintenance.

12) Rain Water Harvesting.

University management has chosen the way volunteers to create own projects towards sustainability, although there are many Higher Education Sustainability Assessment Tools to follow. All groups' initiatives regarding projects have been taken into consideration. Some have failed in early stages but some of them completed successfully which other Higher Education Institutions can adopt.

One year on, overall outputs from groups were reviewed. Reports indicated that 4 meetings were conducted each month with various groups; some providing challenging ideas and its benefit to Campus and some with slow or no contribution. In this article, unexpected findings from Energy Management Group will be discussed. UniMAP's campuses are spread out in various locations in Perlis and remote support departments are located in the State of Kedah and in Kuala Lumpur as well. Amongst these campuses, the new Campus in Pauh, Perlis, was evaluated for sustainability study.

\subsection{Problem Definition}

This paper addresses to reduce energy wastage by utilizing the ground-level understanding and knowledge of University Academicians who are in the field of energy conservation and thereby have an eye for spotting silent energy wastage.

The managements plays a big role in the projects success and how the university might improve its standing. The two-part movement is important, that is, grass-root level and management level. They are both bottom up and top down in that they involve efforts to change. Without the top-down initiatives or shared awareness combined with motivation, possibility of academicians being impartial to the project can result. The aim of this study is to understand how energy usage is managed in UniMAP and whether other requirements by Government departments are pursued. Requirements and suggestions were chosen at random. The specific goal of this study is to show how measurements and data play an important role to make conscious and bring to fore unrealized energy wastage. Collected data from these measurements will assist the organization on suitable actions that will reduce the waste and conform to requirements.

UniMAP's Sustainable Group members believe, much has to be done, since there is commitment by Malaysian Government to reduce carbon footprint up to $40 \%$ by 2020, (United Nations Climate Change Conference, 2009) and Universities or any organization should start implementing green technologies and products in their premises to achieve the target. As a known fact, implementing new technologies using green products are subjected to cost impact. However, it can be done, if proof of concept is presented to convince management that new implementations will result in more benefit than current ones. In any organization, electricity usage should be analyzed to identify unwanted excess or unnecessary usage, which would pave the way to find waste and initiate solutions to reduce. "Over 24 percent of the energy in commercial buildings is used for Heating, Ventilation and Cooling (HVAC). Of this energy, more than half goes to building cooling. In larger buildings, chillers are often used for cooling. Chillers are a type of cooling equipment that produces chilled water to cool air. Making your cooling systems as efficient as possible is an important component of reducing building operating costs. This article addresses energy saving opportunities in chillers" (Improving industrial productivity, through energy-efficient advancements, Progress Energy, US). This paper discusses 2 small projects carried out to reduce electricity consumption in UniMAP.

\section{Operations and Building Maintenance in Malaysia}

Implementing energy saving practices will greatly contribute toward reduction in electricity cost. The Energy Management Group of Sustainable Campus Team at UniMAP were highly motivated to improve operation method of chillers at the Campus, where results in change of practice reduced electricity usage.

Operational and maintenance cost of the building should not be combined, although both expenses are interconnected. To sustain the building performance and maintain the functionality, require investment. Maintenance cost is part of operation cost. Operation in the building will affect the escalation of maintenance cost. To state a few, examples of key operation costs are: 
1) Utility: Electricity and Water

2) Routine Services of assets: Air Conditionings, Lifts, Fire Alarms and Extinguishers.

3) Cleaning: Janitor service.

4) Maintenance: preventive, routine and corrective maintenance of Building.

5) Assessment fees.

Generally, electricity is listed as highest operating expense based on the 5 items listed above. Figure 1 below indicates percentage breakdown of operation cost related to the building. Data was collected from local manufacturing company located in the state of Selangor, Malaysia. Company owns a 4-storey building on an industrial lot measuring 14,876 sq. ft. per floor. Maintenance and operational cost depends on type of building, type of business, number of employees, location and others. The significant and recurring maintenance of building is water and electricity supply, fire systems, lift and air conditioning or heating services. Whereas, external and physical repair such as cracking, painting, doors and windows fixtures, plumbing works/water seepage are occasional.

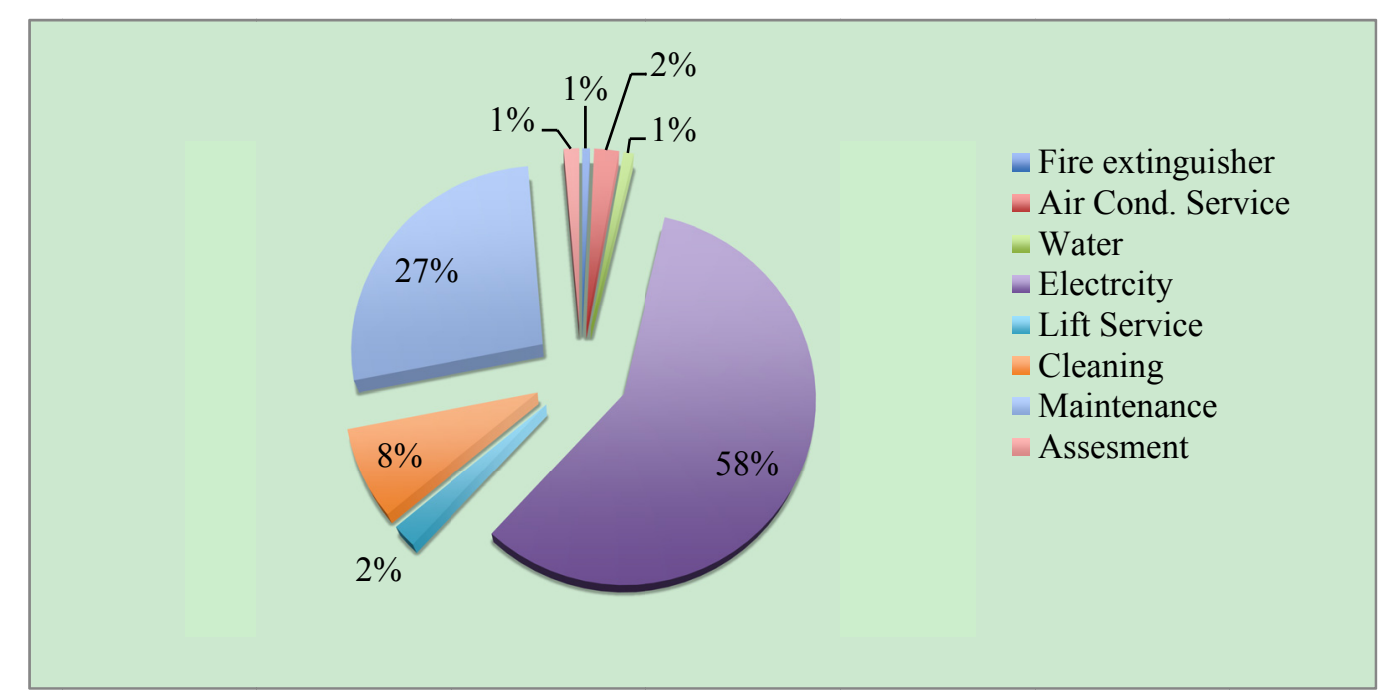

Figure 1. Operation and building maintenance in private company

A study was conducted to compare the operation and maintenance cost of an administrative building. The administrative building at UniMAP, located at Kangar, Perlis was selected for the purpose. The expenses were was almost similar to that of a manufacturing building, with some differences. However, electricity was still the highest expense incurred.

UniMAP hires cleaning services to maintain the building and environment cleanliness. This rated $2^{\text {nd }}$ on expense list. Sludge management utility fee to Indah Water Konsortium Sdn Bhd ("IWK") is a national sewerage company in Malaysia, is included in the breakdown in Figure 2. 


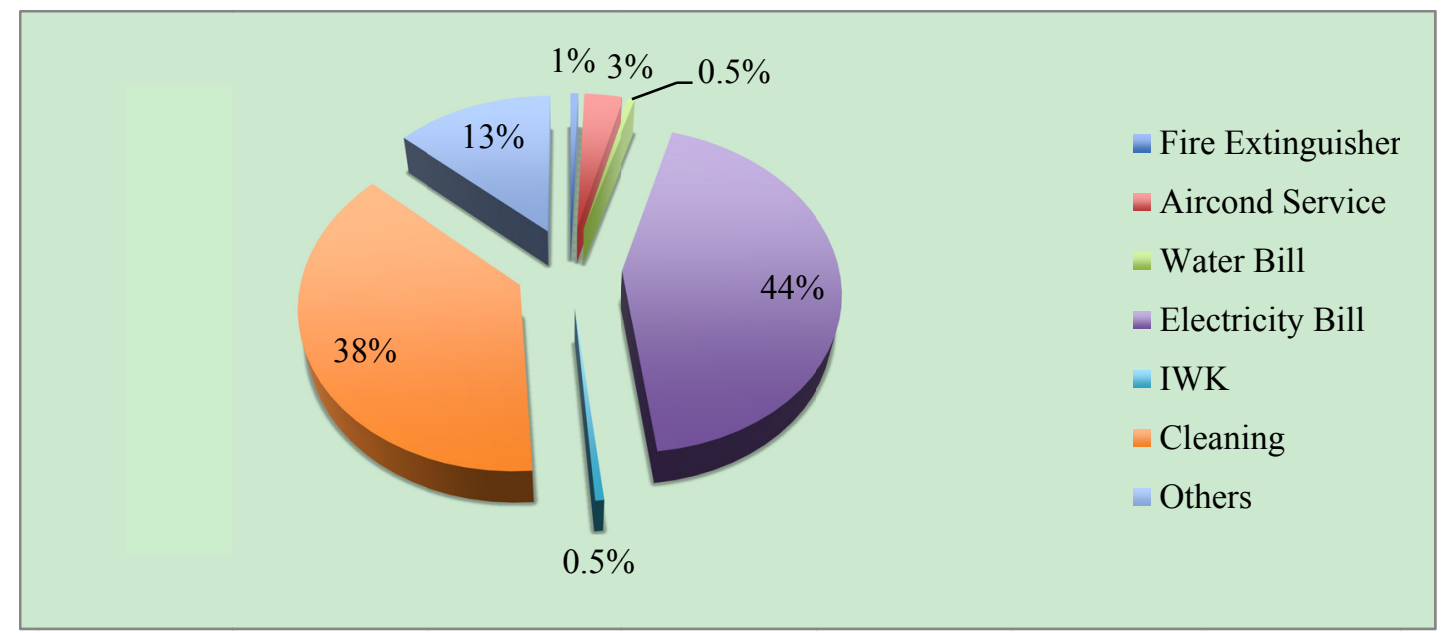

Figure 2. Operation and building maintenance in public university

Figure 1 and Figure 2 respectively illustrate that both administrative and manufacturing building have similar percentage on electricity usage from total expense breakdown for building operation. "Malaysia's climate is categorized as equatorial, being hot and humid throughout the year and the average temperature is $27{ }^{\circ} \mathrm{C}$ " (Malays Travel Guide: Climate of Malaysia). Due to climate, it maybe there is more usage of electricity compare to other countries with different climate. Since, electricity is biggest expense on operation and building maintenance, "Sustainable Campus Energy Management Team" has initiate to reduce electricity usage in Campus.

The 2 small projects are a part of the Sustainable Campus program, under "Sustainable Campus Energy Management Group". There are a number of initiatives carried out by the group, but in this paper, only 2 projects are discussed.

Project 1 is about reducing the chiller energy consumption by staging method. As, chillers' energy consumption contributes for a large percentage of the total electricity consumption of typical buildings. The three chiller plants are chosen to measure the variance of energy consumption (August 2013) between conventional use of chillers and when staging is performed.

Project 2 is about reducing luminous flux in individual areas, such as corridors, labs and conference rooms at two different blocks at Pauh Putra Campus, UniMAP. The new building design was previously expected to include some of the main suggestions by the Government on energy saving and management strategies, such the recommendation from JKR (Public Works Department) into practice. However, results from studies showed otherwise.

\section{Case Study: UniMAP Campus}

\subsection{Increasing Chillers Efficiency}

As mentioned above first project was about increasing efficiency of existing chillers. If chillers is less than 10 years old and not in need of imminent upgrade or replacement, it is unlikely that organization will be able justify the cost replacing the chillers based on energy efficiency savings alone. In this case, best is optimizing existing chillers to work more efficiently. The terminology of chiller efficiency generally expressed in terms of $\mathrm{kW}$ per ton (kW/ton.) A kW is a kilowatt of electrical input. A ton of cooling is equivalent to 12,000 BTU of cooling per hour. More efficient chillers will have lower $\mathrm{kW} /$ ton ratings indicating that they use less electricity to deliver the same amount of cooling.

There is great need to maintain the chillers and increase chiller efficiency, since chillers are responsible for high percentage of electricity usage. Significant energy saving can be achieved, if chillers selection, and sizing are chosen correctly and staging is considered. 7 chillers were chosen in 3 Chiller Plants at Ulu Pauh Campus of UniMAP to define situation. The types and cooling capacity of chillers are shown below in Chart 1 and 2 . 
Chart 1. Type of chillers used in UniMAP

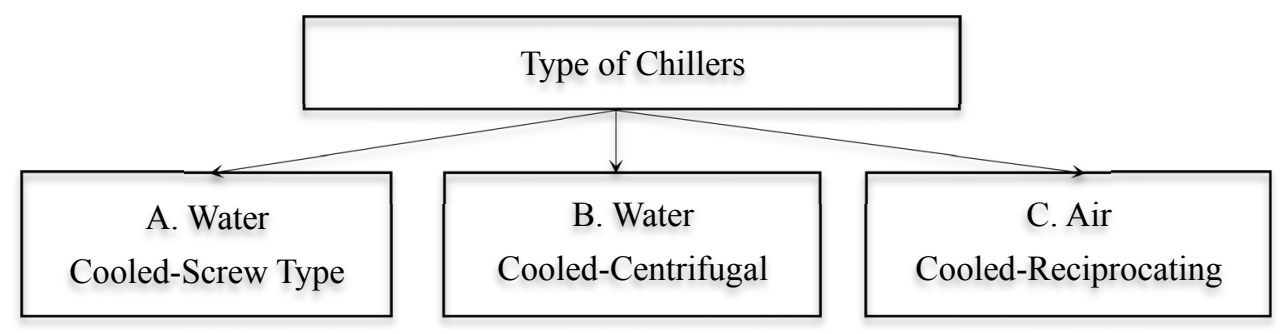

Chart 2. Location of chillers and their capacity

\begin{tabular}{ccccc}
\hline $\begin{array}{c}\text { Chiller } \\
\text { Plant }\end{array}$ & No. Of Chiller & Type & Cooling Capacity & Serving Places \\
\hline 1 & 1 & A & $650 \operatorname{Tr}^{1}$ & School of Manufacturing and Mechatronics \\
& 2 & & $400 \mathrm{Tr}$ & Library \\
2 & 3 & B & $300 \mathrm{Tr}$ & School of Micro-E and Engineering Center \\
& 5 & A & $50 \mathrm{Tr}$ & Lecture Halls \\
\hline
\end{tabular}

${ }^{1} \mathrm{Tr}$ represents Tonnage Refrigerator and indicates capacity of Chillers.

Conventional method of using chillers at UniMAP was to switch on all chillers same time, which there is need time to reach full load under standard rating conditions. With another word, chillers will be using same electricity, but Coefficient-of-Performance (COP) will be less until they reach full load (100\% capacity):

$$
\mathrm{COP}=\mathrm{CP} / \mathrm{IP}
$$

CP-Cooling Power

IP-Input Power

In first project, UniMAP's "Sustainable Campus Energy Management Team" has tried new method for UniMAP to find out how much saving can be achieved with this method. When multiple chillers are used, each chiller's loading schedule must be defined and the schedule will impact total efficiency of chillers when combined. "In fact, it is desirable to use unequal sized chillers within a chiller plant to prolong their operation near full load and therefore, to decrease overall electricity consumption" (Kwok Tai Chan and Fu Wing Yu, 2004). For case study energy consumption in buildings at UniMAP's, 15 minutes interval was chosen to load the chillers.

To acquire reliable data for comparison, it is essential that correct dates be selected, as chillers will not be in operation during study breaks. Main objective of the analysis is to find out whether electricity usage will be reduced, if staging strategy is implemented on current situation. Chart-3 illustrates the study weeks selected for electricity usage. 
Chart 3. Selected weeks for electricity usage study

\begin{tabular}{ccccc}
\hline \multirow{2}{*}{ No } & \multirow{2}{*}{ Days } & $\begin{array}{c}\text { Dates } \\
\text { (Year 2013) }\end{array}$ & $\begin{array}{c}\text { Combined Electricity } \\
\text { Usage }(\mathrm{kWh})^{2}\end{array}$ & Loading Method \\
\hline \multirow{2}{*}{ A } & \multirow{2}{*}{ Mondays } & 15.04 and 06.05 & 68710 & CLST \\
& & 27.05 and 10.06 & 45761 & CLWI \\
\multirow{2}{*}{ B } & Tuesdays & 16.04 and 07.05 & 24939 & CLST \\
& & 28.05 and 11.06 & 25825 & CLWI \\
C & \multirow{2}{*}{ Wednesdays } & 17.04 and 08.05 & 36363 & CLST \\
& & 29.05 and 12.06 & 19611 & CLWI \\
D & Thursdays & 18.04 and 09.05 & 28917 & CLST \\
& & 30.05 and 13.06 & 23592 & CLWI \\
E & Fridays & 19.04 and 10.05 & 30582 & CLST \\
& & 31.05 and 14.06 & 20939 & CLWI \\
\hline
\end{tabular}

${ }^{2}$ Combined total electricity usage in all places as mentioned in Chart-2.

CLST- Chillers loaded same time.

CLWI- Chillers loaded in stages with 15 minutes interval.

"Sustainable Campus Energy Management Team" has taken data for CLST and CLWI for 10 days each. Data has been collected from electricity meter from each plant. As indicated in Chart-3, selected normal usage days are chosen for measurement.

Many factors contribute to the increase or reduction of energy usage based on consumption of components in the building. Meter reading captured was for the entire building electricity usage, inclusive of the locations where multiple chillers are used as mentioned in Chart-2. Statistics shows that electricity expenses for previous months prior to implementation of staging strategy showed significantly higher.

\subsection{Setting up Illumination Level}

Second project, which carried out, by "Sustainable Campus Management Team" is set area illumination level to JKR recommendations. As an example, the recommendations by Malaysian Standards 1525 (MS 1525: Code of Practice on Energy Efficiency and Use of Renewable Energy for Nonresidential Building) on area illumination level seems are yet to be implemented in UniMAP. School of Electrical Systems Engineering of UniMap, "Sustainable Campus Energy Management Team" randomly had chosen corridors, rooms and laboratories on first floors of 2 blocks for illumination level measurement purpose. It is used mostly 2 types of lamps in all area. For example, it has been used T8 and T10 fluorescent lamps in most hostels, libraries, classrooms, labs and corridors, while only in some meeting rooms it has been used compact fluorescent lamps (CFL). The cost-effectiveness of energy-efficient options depends on the intensity of their use and on local electricity costs. Energy efficiency and long life make up for higher first costs most quickly in areas where electricity costs are highest and in applications where maintenance costs are high and usage is most intense. When choosing track lighting, it's important to consider where and how lamps going to be used. Each type of lamp is appropriate in different applications (A). Lamp types-halogen, compact fluorescent, metal halide, and light-emitting diode - also differ in efficacy, life.

Higher Education Institutions should consider in detail when they are building new campuses or change current lamps to more efficient lamps. Choosing right lights may safe a lot in long term, if especially organization is big, like UniMAP.

In project 2, measurement finding showed that, illumination level was almost double than recommended level in selected areas of UniMAP. Data below shows illumination level differences between current situation in UniMap at Pauh Campus (August, 2013), and recommended levels by MS 1525 and JKR (Jabatan Kerja Raya-Department of Public Works). 
Chart 4. Choosing the right lamp type

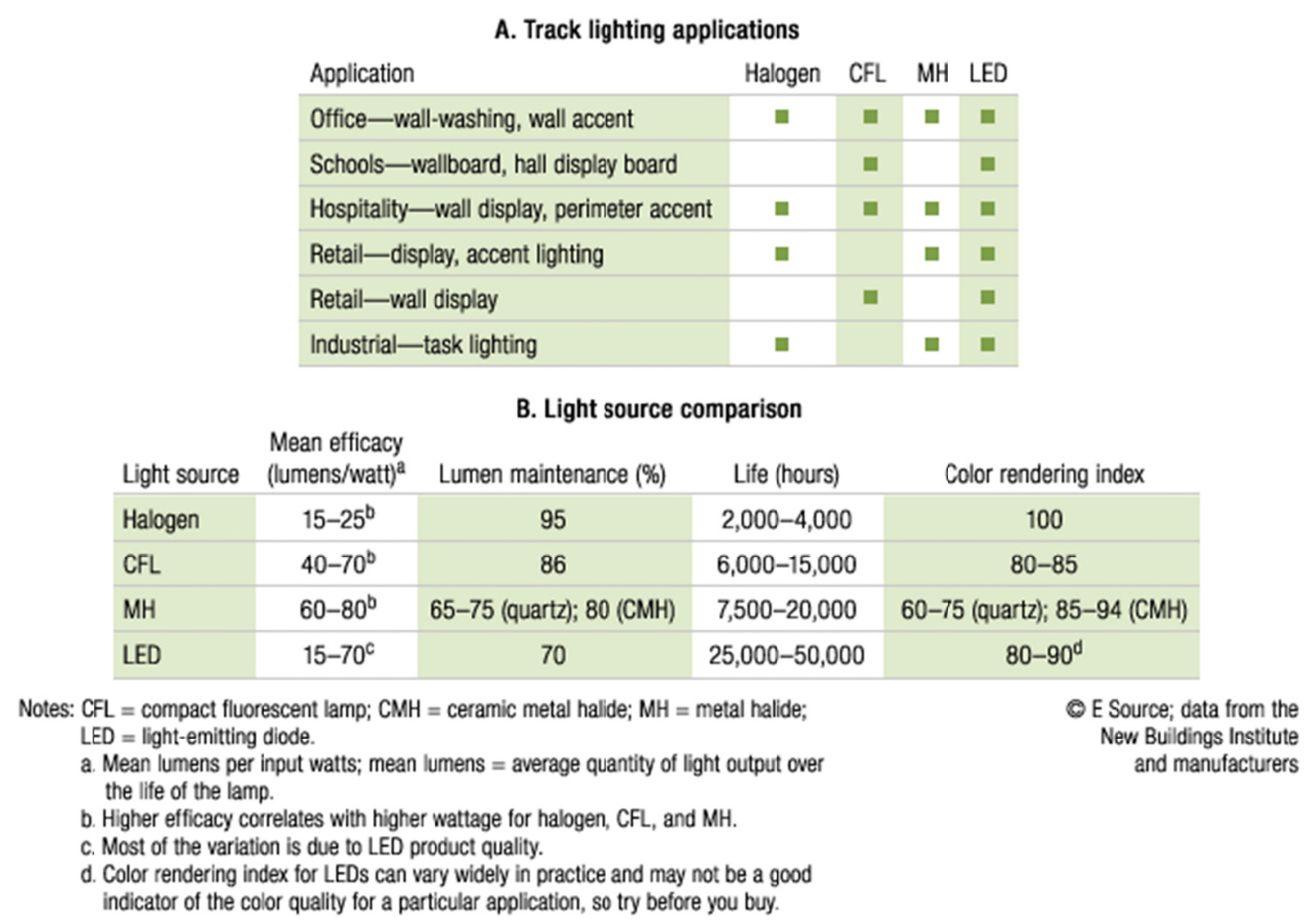

Chart 5. Area illumination level

\begin{tabular}{cccc}
\hline General Building area & MS 1525 Recommendation & JKR Recommendation & UniMap \\
\hline Corridors and Passageway & 50 & 100 & 200 \\
Labs (General) & N/A & 500 & $600-650$ \\
Conference rooms & $300-400$ & 500 & $500-650$ \\
\hline
\end{tabular}

To expand further on this research, "Sustainable Campus Energy Management Team" disconnected some of the lights in selected areas and measurements are carried out by digital light meter. It has been taken average light level throughout a space. It has been used same condition to measure of illumination before and after disconnecting some lamps. Team has decided to use alternative disconnection method to save same light distribution through the area. Team members and students assisted to disconnect the light according to JKR recommendation.

\section{Results and Discussion}

\subsection{Chiller Project}

Chillers have been used widely in large buildings to produce cold water and transfer sensible heat and latent heat from the air to the chilled water, thus cooling and usually dehumidifying the air stream. It is the key component of air conditioning system. The operations of chillers have significant impact on energy consumption and thereby increase demand for electricity.

There are significant efficiency improvements that can only be cost justified at the time of purchase. If a poor purchase decision is made, it may be saddled with high operating costs for many years to come. Need to pay particular attention to the Purchasing Energy-Efficient Chillers and Equipment if chillers greater than 10 years old.

Electricity usage in all places mentioned in Chart- 2 was combined from same day of each week but separated before and after implementation of staging strategy. By combining, a more accurate data comparison was 
acquired for total electricity usage.

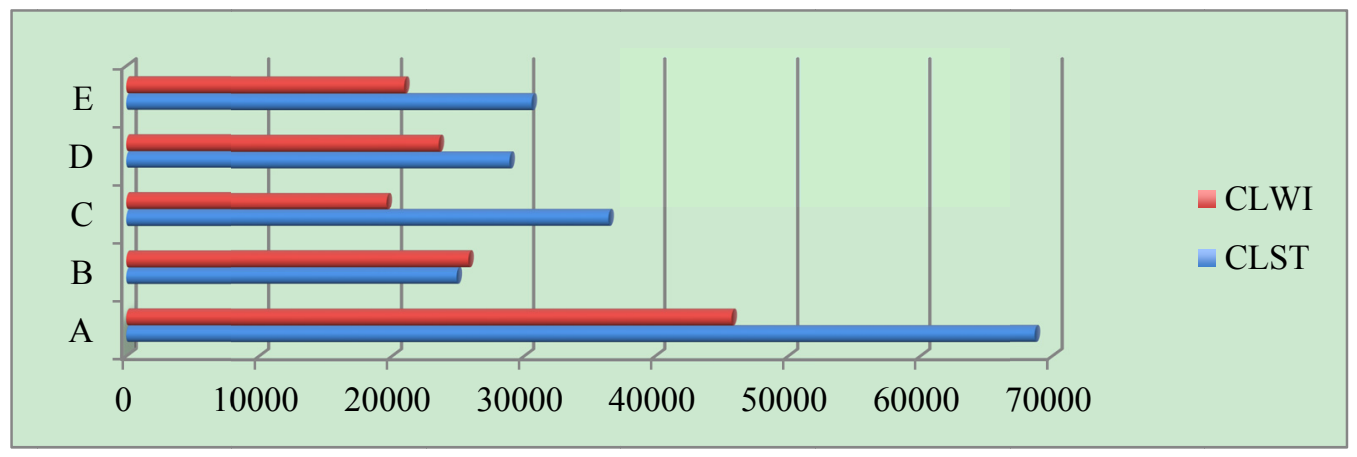

Figure 3. Comparison electricity usage between CLWI and CLST

Figure 3 reveals that energy usage was reduced by approximately $25 \%$, which equals approximately to $53,000 \mathrm{kWh}$ of electricity in just 10 days with staging method.

\subsection{Lux project}

Team has compared electricity usage with before and after disconnecting the some lamps. Saving calculated using simple mathematic method:

$$
\mathrm{S}=(\text { TLEU)-(TLEU-DLEU) }
$$

S-Saving

TLEU-Total Lamps Electricity Usage (kWh)

DLEU-Disconnected Lamps Electricity Usage (kWh)

Chart 6. Saving on Block 1 before and after disconnecting some lamps

\begin{tabular}{cccccc}
\hline \multirow{2}{*}{ TOTAL ENERGY } & $\mathrm{kWh}$ & $\mathrm{kWh}$ & $\mathrm{kWh}$ & $\mathrm{kWh}$ \\
\cline { 3 - 5 } & & $\mathrm{A}$ & $\mathrm{B}$ & $\mathrm{C}$ & Total \\
\cline { 3 - 5 } & & $\mathrm{Avg}$ & $\mathrm{Avg}$ & $\mathrm{Avg}$ & $\mathrm{Avg}$ \\
\hline BEFORE & $14 / 05 / 2013-05 / 19 / 2013$ & 33.18 & 47.26 & 41.81 & 122.25 \\
AFTER & $05 / 21 / 2013-05 / 26 / 2013$ & 21.45 & 26.65 & 41.39 & 89.49 \\
& DIFFERENCEs & -11.74 & -20.61 & -0.42 & -32.76 \\
\hline
\end{tabular}

Chart 7. Saving on Block 2 before and after disconnecting some lamps

\begin{tabular}{cccccc}
\hline \multirow{2}{*}{ TOTAL ENERGY } & $\mathrm{kWh}$ & $\mathrm{kWh}$ & $\mathrm{kWh}$ & $\mathrm{kWh}$ \\
\cline { 3 - 5 } & & $\mathrm{A}$ & $\mathrm{B}$ & $\mathrm{C}$ & $\mathrm{Total}$ \\
\cline { 3 - 5 } & & $\mathrm{Avg}$ & $\mathrm{Avg}$ & $\mathrm{Avg}$ & $\mathrm{Avg}$ \\
\hline BEFORE & $02 / 06 / 2013-06 / 09 / 2013$ & 139.48 & 199.15 & 210.90 & 549.53 \\
AFTER & $06 / 06 / 2013-10 / 06 / 2013$ & 120.64 & 126.41 & 147.15 & 394.20 \\
& DIFFERENCEs & -18.84 & -72.74 & -63.75 & -155.33 \\
\hline
\end{tabular}

Note: A-Laboratories, B-Corridors, and C-Rooms

Summarized result shows after reducing lux level in just 2 blocks for 7 days at Puah Campus, UniMap, electricity usage for only lamps can be reduced by $188.09 \mathrm{kWh}$ :

- Energy consumption before implementation: $671.78 \mathrm{kWh}$. 
- Energy consumption after reducing the lux level: $483.69 \mathrm{kWh}$.

The above demonstrates that if UniMap's "Sustainable Campus Energy Management Team" is able to implement the recommended illumination level in all areas of University, savings could be more than ten fold.

\section{Conclusion}

Within testing period of time, it has been saved approximately $53000 \mathrm{kWh}$ electricity, which equals to 36.5 tons of Carbon. These studies were first step to do much bigger researches and finding indicated there are much more things to do and there are number of hidden problems. These 2 small studies have encouraged management of University and staffs to do more researchers towards sustainability.

The first step to foster a culture of sustainability at University Malaysia Perlis (UniMAP), is to change mindset of staff and students to be environment conscious. This can only be achieved when the policy makers of the University take steps to strengthen its commitment to incorporate energy-saving practices. It is seen that, though there are many architects from some of the world's finest schools, but outputs from their designs towards "green" buildings are small in numbers. It is essential that staff and students be unison in their vision and aspiration to work and study in a Sustainable environment. When that is achieved, transformation can take place. The advantage to start at education camps is because students' observation on their surroundings provides acumen on specific areas and out-of-box mitigation ideas towards sustainability approach. "Higher education has unique academic freedom and the critical mass and diversity of skills to develop new ideas, to comment on society and its challenges, and to engage in bold experimentation in sustainable living" (The Critical Role of Higher Education in Creating a Sustainable Future, by Anthony D. Cortese). Colleges and Universities have an obligation to lead the community. Therefore, the main aspect was agreed upon for development of sustainability to put things into motion.

The result of this case study proves, that there could be many other possible hidden situations where there is waste of University resources in Campus. The new library building that was launched officially in February 2012 is one of the locations in this study. It was expected for some of the research findings to be implemented considered in some aspects of the newly built campus. However, it was found, that there are still many areas for further improvement. It would be a good move for the University, to have a Manager-in-Charge to overlook and control energy consumption, as UniMAP consumes approximately $130,000 \mathrm{kWh}$ energy in a month and it is on the rise. Since financial funding and aid from Malaysian Government is in place, the expenses incurred on energy usage may not be taken as a major concern by the university. This offers an ideal setting for case studies to be conducted. Hence, the importance, of feedback from staff with growing recognition to identify which energy efficiency measures we want to go after will help towards the sustainability.

The scale of the challenge in finding visible issues in campus is big, as it consumes personal time and thus, limited lectures volunteering to do extra tasks. Nevertheless, it was fortunate that there are 12 highly motivated teams of Sustainable Campus of UniMAP who encourage university staffs and students to share their ideas towards to sustainability and assist to solve any issues to carry out studies, which contribute to achieving sustainability in campus. It can be concluded that, more measures should be done in field of Energy, Internal Environment Quality, Sustainable Site Planning, Transportation and Water efficiency, since case study results have lead to reduction in energy use at the campus. UniMAP is large education organization; and it is evident that there is no control on energy usage at present. To tackle this issue, role of energy managers are important and audits must be carried. Investment of some sort is sometimes inevitable on the path of making changes, but forget not, ignorance could be more expensive than the investment.

\section{Annotation}

The Quran says, "Corruption has appeared on land and sea because of what the hands of men have earned, that $\mathrm{He}$ (God) may make them taste a part of that which they have done, in order that they may return (by repenting to God and begging His Pardon)...”(Ar-Rum:41)

\section{Acknowledgement}

I would like to thank all the researchers whose work had contributed towards producing this paper. Special thanks are extended to the management of University Malaysia Perlis, Sustainable Campus Team Members of UniMAP for their dedication, guidance and support for the successful completion of the project.

\section{References}

Ar Zuhairuse MD, D. et al. (2012). Sustainable Development-Education, Business and Management-Architecture and Building Construction-Agriculture and Food Security. InTech, p.114-143. 
Bernard, B. et al. (n.d.). Reducing Energy Consumption by designing for chiller efficiency.

Eric, M. et al. (2012). Greener Buildings Through Site-Specific-Cycle Analysis. Greenbuild International Conference and Expo, p. 28-32.

Jessica, G. et al. (2010). Building energy information systems: User case studies. Springer

John, M. (2011). Environmental Sustainability: A Definition for Environmental Professionals. Journal of Environmental Sustainability, 1, 19-26.

Kwok, T. C. et al. (2004). How Chillers React to Building Loads. Journal of American Society of Heating, Refrigerating and Air-Conditioning Engineers, 52-57.

Mohd., N. A. R. (2010). Tenth Malaysia Plan, 2011-2015. Speech by the Malaysian Prime Minister.

\section{Copyrights}

Copyright for this article is retained by the author(s), with first publication rights granted to the journal.

This is an open-access article distributed under the terms and conditions of the Creative Commons Attribution license (http://creativecommons.org/licenses/by/3.0/). 